\title{
Gender Stereotyping of Leadership Behaviors: Social Metacognitive Evidence
}

\author{
Richard A. Block ${ }^{*}$ and Kevin C. Crawford \\ Department of Psychology, Montana State University, Bozeman, Montana, U.S.A \\ *Corresponding author (Email: block@montana.edu)
}

\begin{abstract}
Gender stereotyping of leadership behaviors is pervasive. Although women and men show few differences in leadership behaviors, experienced male managers rate male and female managers' leadership qualities differently. Participants in this study comprised 107 women and 103 men with little or no management experience. They were asked to estimate how experienced male managers had previously rated women and men on 14 leadership behaviors. We compared these data to those previous data. The participants made social-metacognitive estimates accurately: Their estimates correlated with the previous ratings made by experienced male managers, even though the male managers had access to actual workplace observations. Thus, stereotyping in organizations involves gender stereotypes rather than actual workplace observations. People stereotype other people in organizations because they import stereotypes from non-organizational settings.
\end{abstract}

Keywords - Organizational psychology, Personnel psychology, Gender stereotypes, Social metacognition

\section{Introduction}

Stereotypes are "qualities perceived to be associated with particular groups or categories of people" (Schneider 2004, p. 24). Those qualities include traits, expected behaviors, roles and so on. The process by which perceptions of these qualities influence judgments of individuals is called stereotyping. People exhibit gender stereotyping when they assign traits, behaviors, and roles to individual men and women on the basis of gender. People tend to stereotype men as agentic, or self-assertive and motivated to master, and women as communal, or selfless and concerned with others (Eagly \& Steffen 1984; Heilman et al. 1995; Schein et al. 1989). That is, men are frequently perceived as being aggressive, dominant, forceful, ambitious, independent, self-confident, and self-sufficient; whereas, women are frequently perceived as being affectionate, compassionate, helpful, kind, sympathetic, gentle, and sensitive. One critical reason to study gender stereotyping is that perceptions about how men and women differ often influences behavior toward them.

Men and women are often treated differently in many contexts, such as in the workplace (e.g., Heilman et al. 1995; Jackson et al. 1993; Schein 1975). Women are often stereotyped as lacking the leadership behaviors needed to succeed in managerial and personnel positions (Eagly et al. 1992; Heilman et al. 1989; Martell et al. 1998). Schein et al. (1989) said that male managers "still adhere to the male managerial stereotype and perceive that successful middle managers possess characteristics... more commonly ascribed to men in general than to women in general" (p. 103). Compared to male managers, female managers are judged less favorably on a range of personnel assessments, including hiring, placement, performance reviews, and promotion (Bartol 1999; Bowen et al. 2000; Cohen et al. 1998; Davison \& Burke 2000; Dipboye et al 1975; Eagly \& Karau 2002; Eagly et al. 1992; Heneman 1997; Olian et al. 1988; Perry et al. 1994). Differential treatment based on these gender stereotypes might hamper the advancement of women in management (Pittinsky et al. 2006; Schein 2001). Because upper-level managers apparently display gender-specific strength-and-weakness stereotypes (Heilman \& Eagly 2008; Ryan et al. 2009), it is important to know whether or not gender-stereotypical managerial traits are consistent. It is also important to know whether managerial trait ratings result from processes involving everyday gender stereotypes or actual workplace observations.

Researchers have found that receiving a realistic job preview affects a person's future job satisfaction (Premack \& Wanous 1985). Job expectations that are unrealistically optimistic may decrease job satisfaction, organizational commitment, and job performance (Wanous et al. 1992). Consider a woman who assumes a management position expecting an absence of gender stereotyping and who therefore expects to be perceived and treated no differently than men are. Unrealistic expectations could result if women underestimate men's beliefs in male manager superiority in the workplace. Conversely, a female manager might have an overly pessimistic view of how men stereotype women, leading to another kind of problematic expectations. Pinel (1999), for example, found that women who expect to be discriminated against are more likely than other women to 
generate examples of discrimination-an important consideration in modern litigious workplaces.

Several researchers have studied women's and men's perceptions of female and male leadership behaviors. Martell and DeSmet (2001) investigated male managers' stereotypes of leadership behaviors shown by male versus female middle managers. Their participants included 95 men who were working as managers in a wide range of industries. (They also surveyed 56 female managers. We do not discuss or use those data here, although analyses of those data provide further support for our conclusions.) Most of their participants were in middle management, although substantial minorities were in first-level or senior-level management. They reported a mean of 8.50 years of management experience. Using a 14-category instrument based mainly on the Managerial Practices Survey (Yukl 1994; Yukl et al. 1990), Martell and DeSmet asked male managers to estimate "the percentage of male managers and female managers who are likely to effectively demonstrate [each] leadership behavior" (p. 1226).

This approach, first used by McCauley and Stitt (1978), compares judgments about male and female leadership behaviors by calculating a diagnostic ratio (DR) in which:

$$
\mathrm{DR}=\frac{p(\text { Behavior } / \text { Male Managers })}{p(\text { Behavior } / \text { Female Managers })}
$$

where $p$ is the estimated percentage of male managers or female managers displaying a behavior. Researchers using a DR approach apply a transformation that centers a DR at 0 , if no gender difference is reported (see Results section for details). A transformed DR that is significantly different from 0 (in either a positive or negative direction) reveals a difference in the percentage of male and female managers who were reported to display a particular leadership behavior.

We did not attempt simply to replicate previous research revealing that men show gender stereotyping (e.g., Eagly \& Karau 2002; Martell et al. 1998). We focused instead on an important issue raised by these findings: Are women and men with little or no management experience aware of the ways in which experienced male managers stereotype women and men in organizations?

Asked in this manner, the current research is framed in terms of social metacognition. Metacognition refers to thinking about thinking, or a person's beliefs about his or her own mental states and processes (e.g., Nelson 1999); and social metacognition expands on this by including beliefs about the mental states and processes of other people (e.g., Jost et al. 1998). Using the same survey instrument, DR analysis and male managers' DRs from Martell and DeSmet's (2001) previous study enabled us to compare women's and men's metacognitive judgments of the male managers' stereotypes of female and male managers' leadership behaviors.

In doing so, we tested an important issue: What processes are involved in gender stereotyping of female and male managers? Martell and DeSmet (2001) framed this "question of fundamental importance" in terms of when judgments are "influenced by group-based stereotypes as opposed to an individual's skills and actual behavior" (p. 1228). Unfortunately, their data could not and did not answer this question. Investigating differences between experienced female and male managers' beliefs about leadership abilities of female versus male managers reveals little or nothing about social cognitive processes underlying gender stereotyping in the workplace. The underlying processes might have mainly involved the retrieval of everyday gender stereotypes, rather than the retrieval of specific observations of leadership behaviors. As Atwater et al. (2004) noted: "Numerous studies have been done on the behavior or styles of men and women in management positions. Overall, these studies have shown very few differences" (p. 191). This suggests that when male and female managers show gender stereotyping, they might not be relying on firsthand observations of gender-related differences in managerial behaviors. Instead, they might be accessing previously learned gender stereotypes and importing these everyday stereotypes of women and men into organizational settings.

If actual managers have personal observations of gender differences in the workplace and inexperienced participants' metacognitive estimates are not correlated with those experienced managers' actual ratings, then gender stereotyping in the workplace likely stems from male managers' personal workplace observations of actual gender differences in leadership behaviors. However: if they are significantly correlated, then both inexperienced participants and actual, experienced managers are probably relying on a process of retrieving everyday gender stereotypes, since our inexperienced participants cannot be relying on a process of retrieving personal observations of gender differences in leadership behaviors.

We tested this hypothesis by determining whether women and men with little or no experience in organizational settings are accurate in their metacognitive estimates of how experienced male managers had previously rated women's and men's managerial leadership behaviors. Thus, the present research tests the main hypothesis:

H1: If women and men with little or no experience in organizational settings metacognitively estimate how experienced male managers previously rated various female versus male leadership behaviors, their estimates will be significantly correlated with the actual evaluations made by the experienced male managers.

If they are, then both inexperienced and experienced participants are probably relying on a process of retrieving everyday gender stereotypes of women and men, because inexperienced participants cannot be relying on a process of retrieving their personal, specific observations of gender differences in leadership behaviors. On the other hand, if inexperienced participants' metacognitive estimates are not correlated with experienced managers' actual evaluations, then gender stereotyping in the workplace might stem from male managers' workplace observations of gender differences in leadership behaviors. We also tested a corollary of this hypothesis: If men and women hold similar gender stereotypes, inexperienced women's metacognitive estimates will also be significantly correlated with inexperienced men's metacognitive estimates.

Finally, more specific descriptions of female and male managers might influence participants' estimates (Deaux et al. 
1985). Describing a woman or a man as a successful middle manager might moderate the typical gender stereotype. As did Martell and DeSmet (2001), we administered two versions of the questionnaire, alternately using the terms middle managers and successful middle managers. This enabled us to test a secondary hypothesis:

\section{H2: If the rated person is described as a successful middle manager, the extent to which gender stereotyping influences estimates of leadership behaviors will decrease.}

\section{Method}

\subsection{Participants}

Questionnaires were distributed to 107 women and 103 men. Although the participants had various amounts of business-related education, most of them had little or no firsthand experience as a manager in an organizational setting.

The women who participated varied in business-related education and experience: 10 were students in an entry-level business course (hereafter the Nä̈ve group), 77 were students in upper-level Business and Management courses (hereafter, the Advanced group) and 20 were students either currently in, or recent graduates of, an MBA program (hereafter, the $M B A$ group). A total of 66 of the women (61.7\%) reported that they had no management experience. The other 41 women $(38.3 \%)$ reported a median of only 2.0 years of managerial experience. Of the women who participated, 103 were Caucasian, 1 was Asian, 1 was Hispanic, 1 reported Other and 1 did not report ethnicity. Ages ranged from 18 to $53(M=24.2)$.

The men who participated also varied in business-related education and experience: 23 were students in the Naïve group, 55 were students in the Advanced group, and 25 were students in the MBA group. A total of 60 of the men (57.1\%) reported that they had no management experience. The other 43 men $(41.7 \%)$ reported a median of only 3.0 years of managerial experience. Of the men who participated, 96 were Caucasian, 2 were Asian, 2 were Native American, 2 were Hispanic, and 1 reported Other. Ages ranged from 18 to 51 $(M=24.2)$.

We compared the present data to those of the participants in Martell and DeSmet's (2011) study.

\subsection{Instrument}

The measurement instrument was identical to that used by Martell and DeSmet, with the addition of repeated instructions emphasizing that participants should estimate the way that male managers had previously responded, not simply to report their own estimates. The instrument included 14 categories of leadership behavior, 11 derived from the Managerial Practices Survey (Yukl 1994; Yukl et al. 1990), 1 from the Managerial Leadership Questionnaire (Bass 1985), and 2 other categories considered to be critical to success as a leader. The 14 categories used were: Consulting, Delegating, Inspiring, Intellectual Stimulation, Mentoring, Modeling, Monitoring, Networking, Planning, Problem Solving, Rewarding, Supporting, Team Building, and Upward Influence.

A total of 47 women and 47 men received one form of the instrument (hereafter called the middle-managers condition).
On it, participants were instructed to "estimate what male managers believe to be the percentage of male [female] middle managers who are likely to demonstrate each leadership behavior effectively." Each category of leadership behavior (e.g., Consulting) was described by three concrete examples of actions which constitute that behavior.

Above two lines for rating each item (one for estimating the percentage of female managers showing the behavior and one for estimating the percentage of male managers showing the behavior), the instructions again emphasized that the percentages should be estimated in terms of how previous male managers had responded. A total of 60 women and 56 men received another form of the instrument (hereafter called the successful middle-managers condition), with instructions differing only in the addition of the word successful - that is, "the percentage of successful male [female] middle managers."

\subsection{Procedure}

The survey asked participants to estimate the ratings that male managers had previously made when estimating the percentage of female and male middle-managers displaying each of the 14 leadership behaviors. The survey was randomly distributed between the two forms and, to ensure the anonymity of respondents (and to reduce social desirability responding), it was made clear that responses were anonymous.

\section{Results}

The diagnostic ratio (DR) approach was an important advance in the measurement of gender stereotypes (Bajdo 2005; Duehr \& Bono 2006). McCauley and Stitt's (1978) contribution of the transformed DR measure, centering each measurement at zero, added clarity to the data analyses. For analyses that involve the comparison of two proportions (or percentages), the commonly used measure is the natural logarithm of the odds ratio (Lipsey \& Wilson 2001). The two measures are highly correlated. Our analyses used the transformed DR measure in order to allow direct comparisons with previous data.

Each participant's two metacognitive estimates on each of the 14 leadership behaviors were first converted to a proportion by dividing it by 100 . Separately for each participant, a metacognitive DR was then computed for each of the 14 paired responses (see Equation 1). A transformation was used to ensure parity between DRs ranging from 0 to 1 and DRs ranging from 1 to $\infty$ (cf. McCauley \& Stitt 1978): DRs greater than or equal to 1 were transformed by subtracting 1 from the original DR and DRs less than 1 were transformed by subtracting the inverse of the DR from 1 . Finally, as in previous research, outlying DRs were truncated at -4.50 and +4.50 , and all further statistics were computed using these truncated DRs.

Figure 1 shows a scatterplot of the relationship between women's mean metacognitive DRs and target men's mean actual DRs on each of the 14 leadership behaviors. [The term target men refers to the male participants in Martell and DeSmet's (2001) study.] The 14 pairs of DRs were highly correlated, $r(12)=.76, \mathrm{CI}=.38$ to $.92, p=.002$. Including only female participants who reported no actual management 
experience, this correlation remained high and significant, $r(12)=.73, \mathrm{CI}=.33$ to $.91, p=.003$. These high correlations support our main hypothesis. To the extent that experienced male managers showed a positive DR on a particular leadership behavior (their actual appraisal being that male managers display that behavior more than female managers do), inexperienced women also showed a positive metacognitive DR on that behavior (estimating that male managers would show that kind of gender stereotyping). To the extent that experienced male managers showed a negative DR on a particular leadership behavior (evaluating female managers as displaying that behavior more than male managers do), inexperienced women also showed a negative metacognitive DR on that behavior (estimating that male managers would show that kind of gender stereotyping).

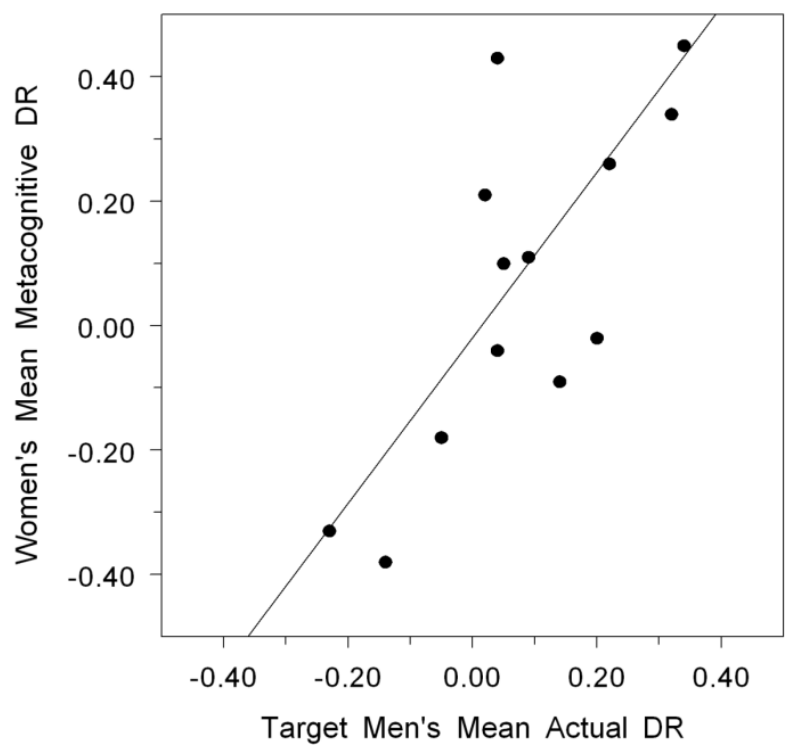

Figure 1. Scatterplot of women's mean metacognitive DR versus target men's mean actual DR for each of 14 leader behavior categories. The best-fitting linear regression line is also shown.

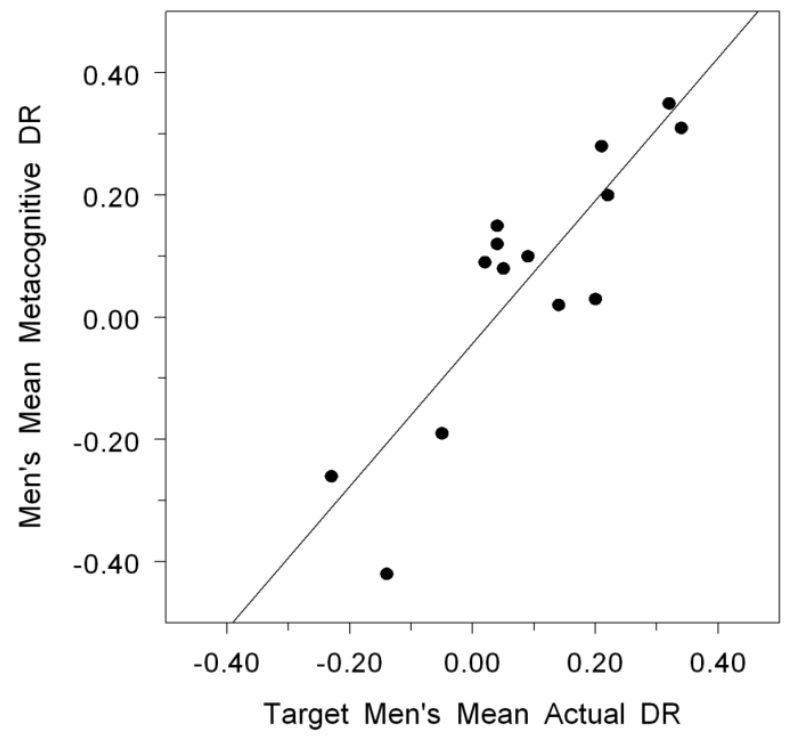

Figure 2. Scatterplot of men's mean metacognitive DR versus target men's mean actual DR for each of 14 leader behavior categories. The best-fitting linear regression line is also shown.

Figure 2 shows a scatterplot of the relationship between men's mean metacognitive DRs and target men's mean actual DRs on each of the 14 leadership behaviors. The 14 pairs of
DRs were highly correlated, $r(12)=.87, \mathrm{CI}=.63$ to $.96, p$ $<.001$. Including only male participants who reported no actual management experience, this correlation remained high and significant, $r(12)=.88, \mathrm{CI}=.66$ to $.96, p<.001$. These high correlations also support our main hypothesis. To the extent that experienced male managers showed a positive DR for a particular leadership behavior, inexperienced men metacognitively estimated the positive metacognitive DR on that behavior; and to the extent that experienced male managers showed a negative DR on a particular leadership behavior, inexperienced men metacognitively estimated the negative DR on that behavior.

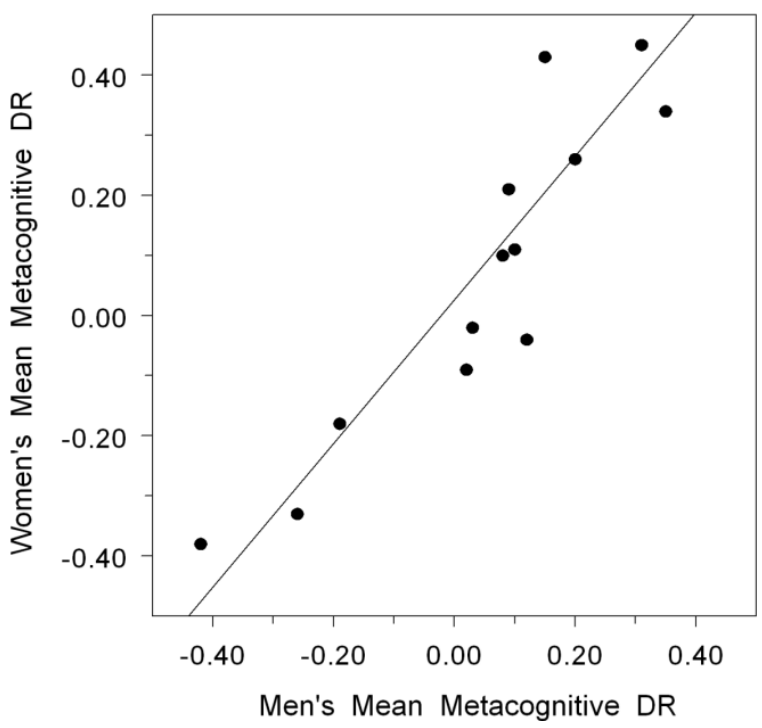

Figure 3. Scatterplot of women's mean metacognitive DR versus men's mean metacognitive DR for each of 14 leader behavior categories. The best-fitting linear regression line is also shown.

Figure 3 shows a scatterplot of the relationship between women's mean metacognitive DRs and men's mean metacognitive DRs on each of the 14 leadership behaviors. The 14 pairs of DRs were highly correlated, $r(12)=.91, \mathrm{CI}$ $=.73$ to $.97, p<.001$. Including only participants who reported no actual management experience, this correlation remained high and significant, $r(12)=.86, \mathrm{CI}=.61$ to $.96, p$ $<.001$. These high correlations support the corollary to our main hypothesis. To the extent that female participants showed a positive metacognitive DR on a particular behavior, male participants also showed a positive metacognitive DR on that behavior; and to the extent that female participants showed a negative metacognitive DR on a particular behavior, male participants also showed a negative metacognitive DR on that behavior.

We conducted several ancillary analyses investigating whether or not metacognitive DRs differed from actual DRs. Suppose that participants' metacognitive estimates for a particular leadership behavior show a mean $\mathrm{DR}=+0.50$ (i.e., they estimated that male managers had reported that a considerably greater percentage of men than women display that behavior). Suppose also that the actual male managers had actually reported a mean DR $=+0.30$ when they evaluated the percentage of men and women as displaying that leadership behavior (i.e., they actually reported that a slightly lower ratio of men to women display that behavior than what our participants estimated they would report). The 
difference between the metacognitive DR and the actual DR is +0.20 . Thus, a DR difference was calculated on each of the 14 behavior categories by subtracting the target men's mean actual DR from each participant's metacognitive DR.

The differences between DRs were analyzed by conducting a 2 (Participant Gender) $\times 3$ (Participant Experience) $\times 14$ (Behavior Category) $\times 2$ (Form) mixed-model multivariate analysis of variance (MANOVA). The main effect of behavior category was significant, $F(13$, $2184)=6.21, p<.001, \eta_{\mathrm{P}}^{2}=.06$, revealing that the differences between the two DRs varied across the 14 behavior categories. No other main effect or interaction effect was significant.

Because the MANOVA revealed a significant effect of behavior category, we compared the women's mean metacognitive DR and the target men's mean actual DR separately for each leadership behavior. Martell and DeSmet
(2001) reported that for only a few behavior categories did the term successful middle managers slightly decrease the target men's tendency to estimate leadership behavior more favorably for men than for women. For that reason, as well as because questionnaire form showed no significant effect in our data, for the sake of simplicity in Tables $1-3$ we averaged DRs across participants who received the two forms of the instrument.

Tables 1-3 show each pair of mean DRs (and SDs), along with the mean difference between each pair of DRs and the effect size $d$. In each table, the difference between each pair of DRs was tested by conducting 14 independent-groups $t$ tests, using a Bonferroni adjustment to control for the overall Type I error rate. Although the Bonferroni adjustment is somewhat conservative, for each $t$ test the power-the probability of finding a medium-size difference $(d=0.50)$ to be significant at $\alpha=.0036$-is nevertheless high (about .84).

Table 1. Women's Metacognitive DR and Target Men's Actual DR for Each Behavior Category

\begin{tabular}{|lrrrrrr|}
\hline \multirow{2}{*}{$\begin{array}{l}\text { Leader behavior } \\
\text { category }\end{array}$} & \multicolumn{2}{c}{ Women $^{\mathrm{a}}$} & \multicolumn{2}{c}{ Target Men } & Difference $^{\mathrm{c}}$ & $\begin{array}{c}\text { Effect } \\
\text { size }(d)\end{array}$ \\
\hline Consulting & -0.33 & 1.02 & -0.23 & 0.96 & -0.10 & 0.10 \\
Delegating & 0.34 & 0.74 & 0.32 & 0.94 & 0.02 & 0.02 \\
Inspiring & -0.02 & 1.02 & 0.20 & 0.91 & -0.22 & 0.23 \\
Intellectual Stimulation & 0.26 & 1.04 & 0.22 & 0.83 & 0.04 & 0.04 \\
Mentoring & -0.04 & 0.97 & 0.04 & 0.87 & -0.08 & 0.09 \\
Modeling & 0.43 & 0.94 & 0.04 & 0.67 & $0.39 *$ & 0.47 \\
Monitoring & 0.21 & 0.94 & 0.02 & 0.71 & 0.19 & 0.23 \\
Networking & 0.11 & 0.85 & 0.09 & 0.91 & 0.02 & 0.02 \\
Planning & 0.10 & 0.81 & 0.05 & 0.93 & 0.05 & 0.06 \\
Problem Solving & 0.45 & 0.81 & 0.34 & 1.00 & 0.11 & 0.12 \\
Rewarding & -0.18 & 0.66 & -0.05 & 0.95 & -0.13 & 0.16 \\
Supporting & -0.38 & 1.02 & -0.14 & 0.84 & -0.24 & 0.26 \\
Team Building & -0.09 & 0.89 & 0.14 & 0.55 & -0.23 & 0.31 \\
Upward Influence & 0.53 & 1.08 & 0.21 & 1.18 & 0.32 & 0.28 \\
Overall $M$ & 0.10 & 0.91 & 0.09 & 0.88 & 0.01 & 0.01 \\
\hline
\end{tabular}

Note. For the women, transformed DRs greater than 0.00 indicate metacognitive estimates that target men would favor male managers, whereas transformed DRs less than 0.00 indicate metacognitive estimates that target men would favor female managers. For the target men, transformed DRs greater than 0.00 indicate actual estimates that favor male managers, whereas transformed DRs less than 0.00 indicate actual estimates that favor female managers.

${ }^{a}$ Mean (and standard deviation) of women's metacognitive DRs. 'Mean (and standard deviation) of target men's actual DRs. 'Mean of women's metacognitive DRs minus mean of target men's actual DRs.

$* \mathrm{p}<.001$

As shown in Table 1, a significant difference between women's mean metacognitive DRs and target men's actual DRs was found for only one leadership behavior category (Modeling), $t(200)=3.42, p=.0008, d=0.47$. Excluding the
Modeling category, the mean effect size of the other 13 differences was small, $d=0.15$. Averaging across all 14 behavior categories, the overall women's mean DR did not differ from the overall target men's mean DR, $t(200)=0.08$, 
$p=.94, d=0.01$. In other words, there was no overall

difference between the women's metacognitive estimates and the target men's actual, reported DRs.

Table 2. Men's Metacognitive DR and Target Men's Actual DR for Each Behavior Category

\begin{tabular}{|c|c|c|c|c|c|c|}
\hline \multirow{2}{*}{$\begin{array}{l}\text { Leader behavior } \\
\text { category }\end{array}$} & \multicolumn{2}{|c|}{$\operatorname{Men}^{\mathrm{a}}$} & \multicolumn{2}{|c|}{ Target Men ${ }^{\mathrm{b}}$} & \multirow{2}{*}{$\begin{array}{c}\text { Difference }^{\mathrm{c}} \\
M\end{array}$} & \multirow{2}{*}{$\begin{array}{l}\text { Effect } \\
\text { size }(d)\end{array}$} \\
\hline & $M$ & $S D$ & $M$ & $S D$ & & \\
\hline Consulting & -0.26 & 0.81 & -0.23 & 0.96 & -0.03 & 0.03 \\
\hline Delegating & 0.35 & 1.08 & 0.32 & 0.94 & 0.03 & 0.03 \\
\hline Inspiring & 0.03 & 1.03 & 0.20 & 0.91 & -0.17 & 0.17 \\
\hline Intellectual Stimulation & 0.20 & 0.86 & 0.22 & 0.83 & -0.02 & 0.02 \\
\hline Mentoring & 0.12 & 0.99 & 0.04 & 0.87 & 0.08 & 0.09 \\
\hline Modeling & 0.15 & 0.84 & 0.04 & 0.67 & 0.11 & 0.14 \\
\hline Monitoring & 0.09 & 0.76 & 0.02 & 0.71 & 0.07 & 0.10 \\
\hline Networking & 0.10 & 0.82 & 0.09 & 0.91 & 0.01 & 0.01 \\
\hline Planning & 0.08 & 0.43 & 0.05 & 0.93 & 0.03 & 0.04 \\
\hline Problem Solving & 0.31 & 0.82 & 0.34 & 1.00 & -0.03 & 0.03 \\
\hline Rewarding & -0.19 & 0.69 & -0.05 & 0.95 & -0.14 & 0.17 \\
\hline Supporting & -0.42 & 0.82 & -0.14 & 0.84 & -0.28 & 0.34 \\
\hline Team Building & 0.02 & 0.60 & 0.14 & 0.55 & -0.12 & 0.21 \\
\hline Upward Influence & 0.28 & 1.02 & 0.21 & 1.18 & 0.07 & 0.06 \\
\hline Overall $M$ & 0.06 & 0.83 & 0.09 & 0.88 & -0.03 & 0.04 \\
\hline
\end{tabular}

Note. For the men, transformed DRs greater than 0.00 indicate metacognitive estimates that target men would favor male managers, whereas transformed DRs less than 0.00 indicate metacognitive estimates that target men would favor female managers. For the target men, transformed DRs greater than 0.00 indicate actual estimates that favor male managers, whereas transformed DRs less than 0.00 indicate actual estimates that favor female managers.

${ }^{a}$ Mean (and standard deviation) of men's metacognitive DRs. 'Mean (and standard deviation) of target men's actual DRs. 'Mean of men's metacognitive DRs minus mean of target men's actual DRs.

As shown in Table 2, no significant difference between men's mean metacognitive DRs and target men's actual DRs was found. Averaging across all 14 behavior categories, the overall men's mean metacognitive DR did not differ from the overall target men's mean actual DR, $t(196)=0.25, p=.81$. The mean effect size of the 14 differences was also small, $d=$ 0.04 .

As shown in Table 3, no significant difference between women's mean metacognitive DRs and men's mean metacognitive DRs was found. Averaging across all 14 behavior categories, the overall women's mean DR did not differ from the overall men's mean DR, $t(208)=0.33, p=.74$. The mean effect size of the 14 differences was also small, $d=$ 0.05 .

\section{Discussion}

We investigated whether relatively inexperienced women and men would have the social-metacognitive ability to judge experienced male managers' actual appraisals of female and male managerial leadership behaviors. We made it clear that participants should respond in the way that they thought male managers had previously responded. Both female and male participants were highly successful in matching target male managers' previous ratings. Across the 14 leadership behavior categories, the pattern of participants' metacognitive DR estimates was highly correlated with that of the target men's DR ratings. This correlation was high both for women's and men's metacognitive estimates and women's and men's metacognitive estimates were also highly correlated. The leadership behaviors that participants thought the target male managers would judge to favor women were estimated accurately and the ones that participants thought the target male managers would judge to favor men were also estimated accurately. This evidence supports our main hypothesis and suggests that gender stereotyping in the workplace involves a process of retrieving everyday gender stereotypes. 
Table 3. Women's Metacognitive DR and Men's Metacognitive DR for Each Behavior Category

\begin{tabular}{|lcccccc|}
\hline Leader behavior & \multicolumn{2}{c}{ Women $^{\mathrm{a}}$} & \multicolumn{2}{c}{ Men $^{\mathrm{b}}$} & Difference & Effect \\
category & $M$ & $S D$ & $M$ & $S D$ & $M$ & size $(d)$ \\
\hline Consulting & -0.33 & 1.02 & -0.26 & 0.81 & -0.07 & 0.08 \\
Delegating & 0.34 & 0.74 & 0.35 & 1.08 & -0.01 & 0.01 \\
Inspiring & -0.02 & 1.02 & 0.03 & 1.03 & -0.05 & 0.05 \\
Intellectual Stimulation & 0.26 & 1.04 & 0.20 & 0.86 & 0.06 & 0.06 \\
Mentoring & -0.04 & 0.97 & 0.12 & 0.99 & -0.16 & 0.16 \\
Modeling & 0.43 & 0.94 & 0.15 & 0.84 & 0.28 & 0.31 \\
Monitoring & 0.21 & 0.94 & 0.09 & 0.76 & 0.12 & 0.14 \\
Networking & 0.11 & 0.85 & 0.10 & 0.82 & 0.01 & 0.01 \\
Planning & 0.10 & 0.81 & 0.08 & 0.43 & 0.02 & 0.03 \\
Problem Solving & 0.45 & 0.81 & 0.31 & 0.82 & 0.14 & 0.17 \\
Rewarding & -0.18 & 0.66 & -0.19 & 0.69 & 0.01 & 0.02 \\
Supporting & -0.38 & 1.02 & -0.42 & 0.82 & 0.04 & 0.04 \\
Team Building & -0.09 & 0.89 & 0.02 & 0.60 & -0.11 & 0.14 \\
Upward Influence & 0.53 & 1.08 & 0.28 & 1.02 & 0.25 & 0.24 \\
Overall $M$ & 0.10 & 0.91 & 0.06 & 0.83 & 0.04 & 0.05 \\
\hline
\end{tabular}

Note. For both the women and the men, transformed DRs greater than 0.00 indicate metacognitive estimates that target men would favor male managers, whereas transformed DRs less than 0.00 indicate metacognitive estimates that target men would favor female managers.

${ }^{a}$ Mean (and standard deviation) of women's metacognitive DRs. 'Mean (and standard deviation) of men's metacognitive DRs. 'Mean of women's metacognitive DRs minus mean of men's metacognitive DRs.

Overall, women's metacognitive estimates of male managers' actual values were not consistently male- or female-biased, but were fairly equally balanced. Although women estimated that experienced male managers would be slightly more male-biased on 8 of the items and slightly more female-biased on 6 of the items, their estimates were relatively accurate on 13 of 14 behavior categories. Men's metacognitive estimates of male managers' estimates also were not consistently biased in one direction. Although inexperienced males estimated that experienced male managers would be slightly more male-biased on 7 of the items and slightly more female-biased on 7 of the items, no significant difference between previous male responses and present male responses was found. Finally, describing managers as successful managers did not significantly moderate participants' abilities to match the target men's pattern of responses.

Our findings reveal that women and men with little or no management experience accurately judge experienced male managers' stereotypes about the leadership behaviors of women versus men. Social-metacognitive estimates of how experienced male managers estimate leadership behaviors of women versus men were highly correlated with the target managers' stereotypes. Although male managers' gender stereotypes were slightly biased in a pro-male direction, women were very accurate in their metacognitive estimates of the leadership behavior categories on which male managers report a gender difference. In addition, men also made accurate estimates and the men's estimates were highly correlated with the women's estimates.

Although we do not try to infer causal processes from correlational evidence, our findings suggest that people rely on gender stereotypes to estimate what other people think about gender stereotypes in the workplace. People sometimes display good social metacognitive skills in assessing how other people respond - for example, in understanding and predicting other people's behaviors and stereotypes (Gilbert 1998). This may be a result of their tendency to "use a stereotype as the basis of their impressions when they believe that the generalized beliefs contained within it are valid for the particular target whom they are judging" (Madon et al. 2006, p. 198). If a person holds a particular gender stereotype, he or she probably assumes that other people also hold that stereotype (Ross et al. 1977). Thus, the seemingly excellent 
social metacognitive skills displayed by our participants apparently involved a process of retrieving information about everyday stereotypes about women and men. This implies that researchers (e.g., Martell \& DeSmet 2001) who have used the DR approach to study gender stereotypes in the workplace have collected data that more heavily reflect experienced managers' everyday (non-organizational) gender stereotypes than their observations of actual workplace differences in leadership behaviors.

Eagly and Steffan (1984) suggested that the stereotyping of women and men stems from observations that women and men are distributed into different occupations (e.g., homemaker vs. employee). Our data reveal that the reverse also occurs: Stereotyping of women and men in specific occupational settings (e.g., middle management) probably stems from everyday (non-organizational) stereotypes of women and men. Relatively inexperienced women and men can accurately predict experienced male managers' stereotypes of men and women's leadership abilities, implying that both the experienced and inexperienced groups are relying on a process of retrieving everyday gender stereotypes.

\section{Acknowledgement}

We greatly appreciated the very helpful and insightful review comments and suggestions provided by Mary L. Rucker, Ph.D., Professor of Communication, Wright State University, Dayton, Ohio.

We also acknowledge the assistance of A. Coin, which determined the authorship order at random.

\section{References}

Atwater, L. E., Brett, J. F., Waldman, D., DiMare, L., \& Hayden, M. V. (2004). Men's and women's perceptions of the gender typing of management subroles. Sex Roles, 50, 191-199.

Bajdo, L. M. (2005). The effect of individual differences on stereotypes of male and female managers. Dissertation Abstracts International: Section B: Sciences and Engineering, 66(3), 1769.

Bartol, K. M. (1999). Gender influences on performance evaluations. In G. N. Powell (Ed.), Handbook of gender in organizations (pp. 165-178). Thousand Oaks, CA: Sage.

Bass, B. M. (1985). Leadership and performance beyond expectations. New York: Free Press.

Bowen, C., Swim, J. K., \& Jacobs, R. R. (2000). Evaluating gender biases on actual job performance of real people: A meta-analysis. Journal of Applied Social Psychology, 30, 2194-2215.

Cohen, L., Broschak, J. P., \& Haveman, H. A. (1998). And then there were more? The effect of organizational sex composition on the hiring and promotion of managers. American Sociological Review, 63, 711-727.

Davison, K. H., \& Burke, M. J. (2000). Sex discrimination in simulated employment contexts: A meta-analytic investigation. Journal of Vocational Behavior, 56, 225-248.

Deaux, K., Winton, W., Crowley, H., \& Lewis, L. L. (1985). Level of categorization and content of gender stereotypes. Social Cognition, 3, 145-167.

Dipboye, R. L., Fromkin, H. L., \& Wiback, K. (1975). Relative importance of applicant sex, attractiveness, and scholastic standing in evaluation of job applicant resumes. Journal of Applied Psychology, 60, 39-43.

Duehr, E. E., \& Bono, J. E. (2006). Men, women, and managers: Are stereotypes finally changing? Personnel Psychology, 59, 815-846.

Eagly, A. H., \& Karau, S. J. (2002). Role congruity theory of prejudice toward female leaders. Psychological Review, 109, 573-598.

Eagly, A. H., Makhijani, M. J., \& Klonsky, B. G. (1992). Gender and the evaluation of leaders: A meta-analysis. Psychological Bulletin, 111, $3-22$.
Eagly, A. H., \& Steffen, V. J. (1984). Gender stereotypes stem from the distribution of women and men into social roles. Journal of Personality and Social Psychology, 46, 735-754.

Gilbert, D. T. (1998). Ordinary personology. In D. T. Gilbert, S. T. Fiske, \& G. Lindzey (Eds.), The handbook of social psychology, 4th ed., Vol. II (pp 89-105). New York: McGraw-Hill.

Heilman, M. E., Block, C. J, \& Martell, R. F. (1995). Sex stereotypes: Do they influence perceptions of managers? Journal of Social Behavior and Personality, 10, 237-252.

Heilman, M. E., Block, C. J., Martell, R. F., \& Simon, M. (1989). Has anything changed? Current characterizations of men, women, and managers. Journal of Applied Psychology, 74, 935-942.

Heilman, M. E., \& Eagly, A. H. (2008). Gender stereotypes are alive, well, and busy producing workplace discrimination. Industrial and Organizational Psychology, 1, 393-398.

Heneman, H. G., III. (1977). Impact of test information and applicant sex. Journal of Applied Psychology, 62, 524-526.

Jackson, L. A., Sullivan, L. A., \& Hodge, C. N. (1993). Stereotype effects of attributions, predictions, and evaluations: No two social judgments are quite alike. Journal of Personality and Social Psychology, 65, 69-84.

Jost, J. T., Kruglanski, A. W, \& Nelson, T. O. (1998). Social metacognition: An expansionist review. Personality and Social Psychology Review, 2, $137-154$.

Lipsey, M. W., \& Wilson, D. B. (2001). Practical meta-analysis. Thousand Oaks, CA: Sage.

Madon, S., Guyll, M., Hilbert, S. J., Kyriakatos, E., \& Vogel, D. L. (2006). Stereotyping the stereotypic: When individuals match social stereotypes. Journal of Applied Social Psychology, 36, 178-205.

Martell, R. F., \& DeSmet, A. L. (2001). A diagnostic-ratio approach to measuring beliefs about the leadership abilities of male and female managers. Journal of Applied Psychology, 86, 1223-1231.

Martell, R. F., Parker, C., Emrich, C. G., \& Crawford, M. (1998). Sex stereotyping in the executive suite: "Much ado about something." Journal of Social Behavior and Personality, 13, 127-138.

McCauley, C., \& Stitt, C. L. (1978). An individual and quantitative measure of stereotypes. Journal of Personality and Social Psychology, 36, 929-940.

Nelson, T. O. (1999). Cognition versus metacognition. In R. J. Sternberg (Ed.), The nature of cognition (pp. 625-641). Cambridge, MA: MIT Press.

Olian, J. D., Schwab, D. P., \& Haberfeld, Y. (1988). The impact of applicant gender compared to qualifications on hiring recommendations. Organizational Behavior and Human Decision Processes, 41, 180-195.

Perry, E. L., Davis-Blake, A., \& Kulik, C. T. (1994). Explaining gender-based selection decisions: A synthesis of contextual and cognitive approaches. Academy of Management Journal, 19, 786-820.

Pinel, E. C. (1999). Stigma consciousness: The psychological legacy of social stereotypes. Journal of Personality and Social Psychology, 76, 114-128.

Pittinsky, T. L., Shih, M. J., \& Trahan, A. (2006). Identity cues: Evidence from and for intra-individual perspectives on positive and negative stereotyping. Journal of Applied Social Psychology, 36, 2215-2239.

Premack, S. L., \& Wanous, J. P. (1985). A meta-analysis of realistic job preview experiments. Journal of Applied Psychology, 70, 706-719.

Ross, L. S. U., Greene, D., \& House, P. (1977). The false consensus effect: An egocentric bias in social perception and attribution processes. Journal of Experimental Social Psychology, 13, 279-301.

Ryan, M. K., Haslam, S. A., Hersby, M. D., Kulich, C., \& Wilson-Kovacks, M. D (2009). The stress of working on the edge: Implications of glass cliffs for both women and organizations. In Barreto, M., Ryan, M. K., Schmitt, M. T. (Eds.), The glass ceiling in the 21 st century. Understanding barriers to gender equality (pp. 153-169). Washington, DC: American Psychological Association.

Schein, V. E. (1975). Relationships between sex role stereotypes and requisite management characteristics among female managers. Journal of Applied Psychology, 60, 340-344.

Schein, V. E. (2001). A global look at psychological barriers to women's progress in management. Journal of Social Issues, 57, 675-688.

Schein, V. E., Mueller, R., \& Jacobsen, C. (1989). The relationship between sex role stereotypes and requisite management characteristics among college students. Sex Roles, 20, 103-110.

Schneider, D. J. (2004). The psychology of stereotyping. New York: Guilford Press. 
Wanous, J. P., Poland, T. D., \& Premack, S. L., \& Davis, K. S. (1992). The effects of met expectations on newcomer attitudes and behaviors: A review and meta-analysis. Journal of Applied Psychology, 77, 288-297. Yukl, G. (1994). Leadership in organizations. Englewood Cliffs, NJ: Prentice Hall.
Yukl, G., Wall, S., \& Lepsinger, R. (1990). Preliminary report on validation of the managerial practices survey. In K. E. Clark, \& M. B. Clark (Eds.), Measures of leadership (pp. 223-237). West Orange, NJ: Leadership Library of America. 